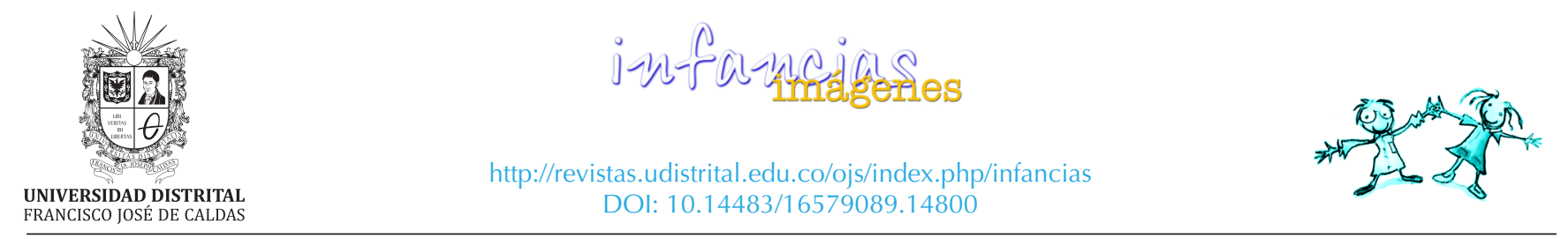

IMÁGENES DE INVESTIGACIÓN

\title{
La participación infantil para la construcción de ciudadanos planetarios $^{*}$
}

\section{Child participation for the construction of planetary citizens}

\author{
Sandra Johanna Jaramillo Rodríguez ${ }^{(\mathbb{B}}$, Mónica Alejandra Mejía Herrera $^{2}$
}

Para citar este artículo: Jaramillo, S. J., Mejía, M. A. (2020).

Recibido: 10-09-2019 - Aceptado: 26-06-2020

La participación infantil para la construcción de ciudada-

nos planetarios. Infancias Imágenes, 19(2), 96-108

\section{Resumen}

Se expone el resultado de la investigación-acción participativa cuya pregunta central fue: ¿cómo fortalecer la participación para la formación de ciudadanos planetarios a través de la pedagogía de la colegio Marruecos y Molinos? Crear escenarios de participación de los niños y niñas en la escuela trae desafíos, tanto en la relación educativa como en los dispositivos pedagógicos manejados. El proyecto evidencia los procesos de formación de la ciudadanía y los diferentes niveles de participación de los estudiantes, así como el papel del adulto en estos procesos de aprendizaje. Para comprender los tipos de participación se tomaron a Hart (1993) y Tonucci (2002). Para la noción de ciudadanía planetaria a Morin (1999), Gadotti (2000) y Leff (2000). Y, por último, a Restrepo (2004), Parra (2002), Schön y Zabalza (1998) como fuentes de reflexión para la construcción de un conocimiento propio de nuestro accionar. Palabras clave: rol del adulto, participación infantil, ciudadanía planetaria, saber pedagógico.

\begin{abstract}
Albstract
The results of the participatory action research are exposed: ¿how to strengthen participation for the formation of planetary citizens through the pedagogy of the question in the boys and girls of the second grade of the Marruecos and Molinos school? Creating scenarios for the participation of boys and girls in school brings challenges both in the educational relationship and in the pedagogical devices used. The project shows the processes of citizenship formation and the different levels of student participation are evidenced, as well as the role of the adult in these learning processes. To understand the types of participation, Hart (1993) and Tonucci (2002) were used. For the notion of planetary citizenship Morin (1999), Gadotti (2000) and Leff (2000). And finally to Restrepo (2004), Parra (2002), Schön and Zabalza (1998) as sources of reflection for the construction of our own knowledge of our actions.
\end{abstract}

Keywords: role of the adult, child participation, planetary citizenship, pedagogical knowledge.

\footnotetext{
Investigación-acción en el aula resultado del trabajo investigativo y proyecto de tesis realizada desde marzo hasta noviembre de 2018, con niños y niñas de grado segundo de la jornada mañana del colegio IED Marruecos y Molinos ubicado en Bogotá, Colombia.

1 Licenciada en Pedagogía Infantil, Universidad Distrital Francisco José de Caldas. Correo electrónico: sandrajohajr@gmail.com. Orcid: https://orcid.org/0000-0001-6526-0928

2 Mónica Alejandra Mejía Herrera, licenciada en pedagogía infantil de la Universidad Distrital Francisco José de Caldas. Correo electrónico aleja.130945@gmail.com. Orcid: https://orcid.org/0000-0003-4186-0608
} 


\section{Introducción}

Con el ánimo de contribuir al análisis y transformación de la realidad colombiana, y no pasar por alto la apremiante necesidad de cambios en la educación de nuevas generaciones, el proyecto de investigación y pedagógico desarrollado reflexiona sobre las situaciones sociales que no permiten la consolidación de una ciudadanía comprometida con la adecuada convivencia con todos y todo lo que nos rodea. El paradigma de la ciudadanía planetaria es precisamente eso: asumir responsabilidad por y desde su territorio local y se expande a lo global, teniendo como referencia el mundo como un todo.

La educación impartida en la escuela se enfoca en una actitud de competencia e individualidad; prácticas que algunos estudiantes y profesores perpetúan incluso en el colegio escenario de estudio. En el contexto escolar es recurrente la idea de que participar es la acción de levantar la mano. De allí que sean las mismas maneras de participar las que se promueven en este espacio y que los niños y niñas hayan construido una noción limitada del concepto. Con el propósito de disminuir estas actitudes se promovió la participación de los niños y las niñas por medio de la pedagogía de la pregunta de Paulo Freire y la implementación de actividades que ellos mismos dirigían, con el fin de construir posturas desde el paradigma de la ciudadanía planetaria. La pertinencia de este radica en la formación de ciudadanos que participen en el cuidado de su contexto; ya sea desde su autonomía (Tonucci, 1997; Gallego, 2015) o cualquier nivel de participación (Hart, 1993).

Hablar de ciudadanía planetaria no es un concepto fácil de entender, pero el proyecto promovió una noción de ciudadanía asociada al cuidado del planeta y la naturaleza debido a la relación que establecieron con los temas trabajados en el proyecto de aula. De esta manera se reflexiona no solo el impacto que tuvo el proyecto en el contexto sino de nuestro papel como docentes para la construcción de saber pedagógico.

\section{Metodología}

El proyecto se desarrolló con niños y niñas de estratos socioeconómicos de 2 a 3, era un grupo de
38 estudiantes del grado segundo de un colegio distrital de Bogotá ubicado en el barrio Molinos. Se trabajó a partir de la investigación-acción en el aula (Elliot, 2000), planteando en un inicio dos categorías: participación infantil y ciudadanía planetaria; cada una con sus respectivas subcategorías. Posteriormente, en un ejercicio de inmersión y práctica in situ surgió la categoría saber pedagógico. Los datos se recolectaron a partir del taller y trabajos realizados por los estudiantes. Se realizó un ejercicio cartográfico cuya intención fue que los estudiantes contarán los modos en los que participan en sus casas. Se usó el diario de campo para sistematizar la información obtenida. Luego, se categorizó mediante una bitácora para su posterior organización en una matriz de análisis. La escritura se dio en dos niveles: el primero desde un enfoque relacional entre los hallazgos y la teoría; y el segundo, en la construcción del saber pedagógico.

Se buscaba con esta metodología que los participantes fuesen sujetos activos en la investigación, así como el crear diálogos y relatos con los que las investigadoras interpretaron y construyeron conocimiento con los demás participantes por medio de una reflexión sobre una problemática en común. Sin embargo, la dependencia del niño o niña hacia el adulto en la toma de decisiones fue un limitante. Por ello, fue necesario en repetidas ocasiones problematizar, por medio de la pregunta, situaciones que llevaran a los niños y niñas a buscar respuestas por ellos mismos. Por ejemplo: ¿cómo sabes que el adulto tiene la razón?, ¿por qué un niño o niña no puede dar una clase?, ¿quién es Chuky en nuestra realidad? Como producto de ello, se transformaron las relaciones del docente con sus alumnos, con los saberes que tiene y, por supuesto, con la implementación del proceso educativo.

\section{Resultados}

La participación en el contexto escolar y familiar En el inicio de la investigación se reconocieron tres tipos de participación que la escuela permite. La primera sucede cuando la docente pregunta y el estudiante levanta la mano para pedir la palabra; por lo general, su aporte debe ser acorde a lo que el adulto desea escuchar. Al respecto, Tonucci 
(2002) menciona que dar la palabra no significa que se deba simplemente preguntar y ver quién levanta la mano primero, sino en crear situaciones propias para que los niños y niñas puedan expresarse. El segundo se encuentra en la representación de estudiantes en eventos escolares, quienes son elegidos por su habilidad en el discurso oral; en estos eventos escolares suelen ser elegidos aquellos estudiantes que ya cuentan con habilidades de expresión oral, por lo que se obstruye la participación de estudiantes diferentes a los mismos. Por último, es recurrente la irrupción de estudiantes de grados mayores, puesto que deben desarrollar actividades obligatorias con otros estudiantes para cumplir con los requerimientos que solicita una materia determinada. Las dos últimas se enmarcan en una manipulación simbólica que distorsiona la participación, la cual es una herramienta de quienes detentan el poder. Se trata de engañar a la población en un supuesto proceso de participación en el que no se les informa correctamente ni tampoco se les consulta de forma adecuada (Hart, 1993), pues las intenciones de estas actividades son desconocidas por los estudiantes. Por la misma razón, Shier defiende que:

La participación no puede ser pensada exclusivamente en términos de integración en actividades, es necesario trascender esta idea y apropiarse de la concepción de la participación como derecho y de las posibilidades que concede. En tal sentido, es importante el reconocimiento de sí mismo y de la capacidad de actuación dentro de los escenarios sociales, representados en la familia, la escuela y la comunidad. (2010, p. 6)
Jaramillo y Mejía (2019) mencionan cómo los niños y niñas participan mediante la resolución de conflictos; en los cuales pueden asumir dos funciones: como mediadores y como agentes que realizan juicios morales. En la primera, la expresión de afecto será la manera como median para que sus compañeros resuelvan el conflicto. Una situación lo ejemplifica: se pregunta a los niños y niñas de grado segundo del colegio Marruecos y Molinos cómo podríamos solucionar el problema. Comentaron que pidiendo perdón; pero ninguno de los niños implicados quiso aceptar sus errores. Un niño comenta "toca abrazarnos" y abraza a todos. La segunda función se caracteriza en que los niños y niñas aportan de manera verbal sus conocimientos, así expresan lo que creen que está bien o mal según la acción que el otro sujeto realiza. Es decir, en las edades de 7 a 9 años participan desde una postura moral. Se evidencia un caso concreto en una entrevista realizada por los niños y las niñas a otros estudiantes del colegio. El objetivo era conocer su opinión sobre la importancia de no botar basura y, aun conociendo la metodología y finalidad del ejercicio, repitieron a los compañeros lo que debían o no hacer. Esta actitud se debe a que no les interesaba conocer lo que opinaban los demás, sino simplemente hablar directamente de la importancia de la información.

\section{¿Para qué participan los niños y las niñas?}

Los espacios de participación que permite la escuela generan que los niños y niñas construyan significados sobre el para qué deben participar. Desde el diálogo con ellos y a partir de la observación se
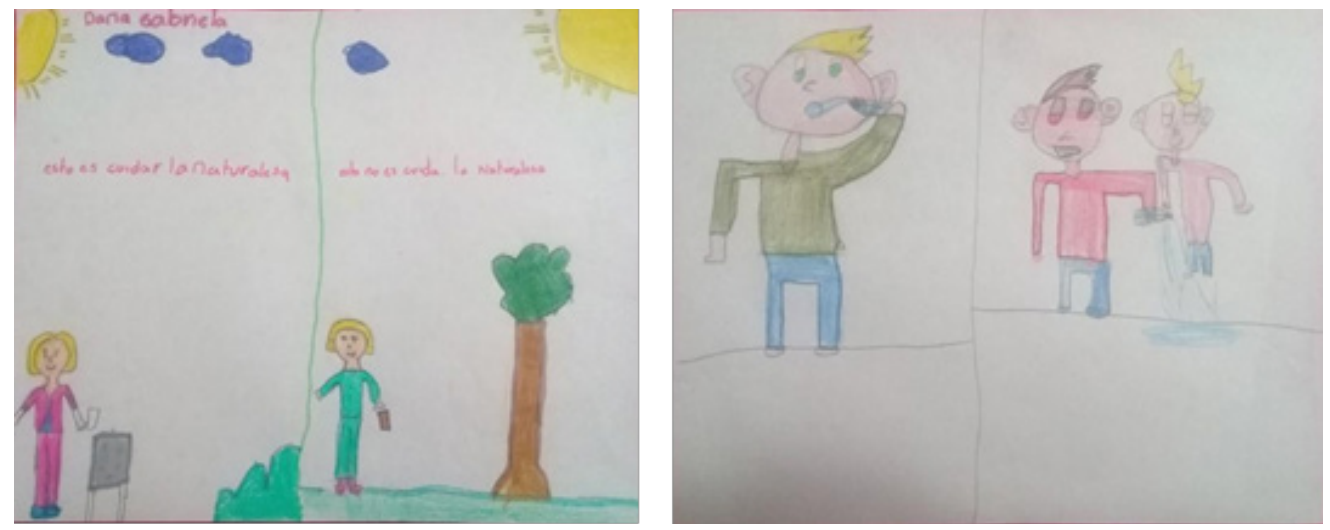

Figura 1. Fotos de trabajos de entrevista de los niños y niñas. 
evidenció que en el colegio Marruecos y Molinos se encuentran cuatro razones por las que lo hacen:

1. Los estudiantes levantan la mano porque quieren mantener una relación de empatía. Cuando el adulto pregunta el estudiante tenderá a romper esos silencios incómodos algunas veces con comentarios que están fuera del tema o pregunta realizada.

2. Necesidad de levantar la mano para demostrar que participan, aun cuando no tengan nada que decir. Es recurrente que cuando el docente concede la palabra contesten: "se me olvidó".

3. Aun cuando no lo expresan verbalmente, se encuentra la importancia que tiene para algunos que sus ideas e intervenciones sean valoradas para sentirse importantes. Su participación forma parte de un reconocimiento desde lo propio de sus ideas y su posición como sujeto activo.

4. El sistema de evaluación ha producido que la nota funcione como un motivador. La participación es importante en la medida en que se recibe un reconocimiento cuantitativo, pero no en cuanto se aprende y construye conocimiento.

\section{La participación de los niños y las niñas en el proyecto pedagógico}

Se reconoce, a partir del diálogo e interacción con los niños y niñas, la necesidad de dotar de valor otras formas de participación. Por tal, el ejercicio pedagógico se trabajó a partir del proyecto de aula que tuvo como nombre "El mundo bajo el agua" con tres ejes principales (relación con el otro, cuidado del agua y el manejo de la basura), los cuales fueron concertados con los niños y niñas tras la etapa de caracterización. Se presentan cuatro maneras de participación diferentes a las ya mencionadas: participación por enunciación, participación desde la reflexión y la propuesta, participación desde la acción y participación representativa. Estos se explican a continuación.

\section{Participación por enunciación}

Se basa en repetir la información que la docente ha dicho. Se limita a la enunciación del problema y en comentar que algo es bueno o malo, sin argumentar por qué se dice. Según Hart (1993), este tipo de participación pertenece a asignado pero informado. Los estudiantes reconocen que tienen un papel significativo, son conscientes de la intención del proyecto y sus aportes son voluntarios. Sin embargo, simplemente repiten las decisiones o el discurso de quien propone las actividades.

La tendencia de que los niños repitan sin mayor reflexión sobre lo que se dice es generada por experiencias de la dinámica social que truncan la participación infantil (Hart, 1993). Estas resultan ser inhibidoras de la participación debido a la incapacidad de ver y aceptar otros puntos de vista. En este sentido, si se ve al adulto como aquel que tiene la razón el niño y la niña cohibirán sus opiniones o aportes y repetirá los que son considerados correctos. Esto se manifestó cuando los estudiantes perdían su espontaneidad al hablar sobre sus temas de interés, pues se demostraba miedo constante al creer que no estaban diciendo lo que el adulto quería escuchar. Como consecuencia, sus discursos se respaldan desde conceptos escolares, pero no por sus propias experiencias vividas en la cotidianidad.

Participación desde la reflexión y la propuesta

El estudiante trasciende de una repetición del discurso a proponer ideas y hacer aportes para la construcción del conocimiento o apropiación del proyecto realizado. En términos de Hart (1993), Tonucci (1997) y Gallego (2015), se reconoce la autonomía de los niños y las niñas como su capacidad para involucrarse, elegir, decidir y actuar por sí mismos. Su protagonismo infantil tiene como propósito manifestar libremente sus pensamientos, sus sentimientos, sus emociones y el apropiarse de los diferentes escenarios públicos.

Algunas propuestas que los niños y niñas realizaron para solucionar problemáticas de su cotidianidad fueron: "cerrar la llave cuando nos cepillamos", "comprometerse a no volver a botar basura", "salir con los papás en un recorrido donde recojan basura", "jugar con ellos para mejorar las relaciones entre la familia" (Jaramillo y Mejía, 2019).

Otro ejemplo que demuestra la participación autónoma de algunos estudiantes, construida a partir del diálogo basado en los intereses de los niños y 
las niñas, fue el caso de Fernando ${ }^{1}$. Él mencionó lo importante que es Ilevar a la caminata en la quebrada carteleras con mensajes para los papás y los vecinos sobre cómo cuidar el agua. En el momento de la caminata propuso, además, cantar una canción:

¡Vamos, vamos, vamos a cantar! ¡Vamos, Vamos a investigar! ¡Porque el agua tenemos que cuidar y la quebrada vamos a ir a salvar!

Los niños y niñas en este tipo de participación aportan desde sus reflexiones. Los debates producen en ellos mayor reflexión sobre lo que se habla y una mayor capacidad de argumentación. Un ejemplo es el caso del estudiante que dice "jugar es una forma de participar". Esta afirmación fue tema de discusión cuyas reflexiones fueron de sus compañeros. La intención no fue juzgar ni decir quién tuvo la razón, sino promover un diálogo argumentado frente a las distintas respuestas.

En esta medida, se comprendió que en algunos casos no es solo un proceso en el que el niño se aprende un discurso y lo repite, sino que este lo asocia a diferentes situaciones al tiempo que piensa y transforma sus necesidades.

\section{Participación desde la acción}

Hart (1993) resalta que si un niño o niña considera como propio un proyecto habrá un impacto positivo en su forma de participar. Los proyectos iniciados y dirigidos por los niños demuestran no solo reflexión del discurso, sino que además ejercen acciones en otros contextos. Como, por ejemplo:

- En un recorrido realizado por la quebrada Chiguaza se botó intencionalmente un papel. Dos niñas se dieron cuenta, una lo señaló, pero ninguna hizo nada. Daniel simplemente recogió el papel y lo botó en la basura.

- Otra manera de evidenciar el trasfondo del accionar del niño es por medio de la conversación que se tiene con la madre. Ella comenta que él ha empezado a guardar todos los paquetes en su bolsillo que luego encuentra cuando lava la ropa. Además, anota

1 Los nombres de los estudiantes han sido cambiados para proteger su identidad. atento en su diario y regaña a sus familiares por botar un papel en la calle.

Las situaciones descritas esclarecen esas otras maneras de participar que tienen los estudiantes. Las cuales deben ser foco de atención pues al no ser explícitas es necesario "ir más allá" para poder evidenciarlas.

De esta manera, se relata la participación en la que la acción toma más relevancia. Es decir, si en el anterior tipo se resaltaba la capacidad de reflexionar las ideas para llegar a proponer diferentes proyectos, en este se enmarca el llevar a cabo dichos ejercicios. Con ello, los estudiantes no solo difunden un discurso, además, pueden llegar a transformar su entorno.

\section{Participación representativa}

Desde la definición de la Real Academia de la Lengua Española, la participación democrática es la forma de gobierno en la que el poder político es ejercido por los ciudadanos y dicho es ejercido de forma directa o por medio de representantes. Es decir, se habla de cómo los ciudadanos de una manera responsable seleccionan a un líder que proyecte las ideas de la mayoría de los integrantes de la sociedad. Sin embargo, en el caso de los niños y niñas se evidencia que existe una distorsión de la noción, configurándose de tal manera que se convierte en una participación representativa (Gallego, 2015). En esta se elige a una persona para que hable por todos, desligándose de todo tipo de responsabilidad y colaboración frente al tema.

Por otro lado, existen casos en el que es el mismo niño quien asume de manera autónoma la dirección del grupo. Sin embargo, este tipo de líder suele ser totalmente autoritario, pues toma decisiones que cree pertinentes sin importar lo que los demás piensen.

En este tipo de participación se resalta la falta de autonomía por parte de los estudiantes no solo cuando deben tomar decisiones con el adulto, sino también en ejercicios de elección con sus pares. Este caso se evidenció durante las votaciones del tema del proyecto en el aula, pues cuando fue el turno de Fernando les dijo a sus compañeros:

¡Vamos, Vamos! ¡El mundo bajo el agua, el mundo bajo el agua! 
De ahí en adelante todos votaron por ese tema. Se identifica que cuando un estudiante construye cierto poder en el aula puede influir en las decisiones de sus compañeros, los cuales deciden sin tener en cuenta lo que realmente quieren, sino que lo hacen por la incitación provocada por su par. Las nociones que el niño y la niña han adquirido frente a este tipo de participación hacen que sus actitudes de liderazgo disminuyan, debido a que otorgan sus responsabilidades a otras personas negando la posibilidad de asumirse como sujetos activos en un proceso.

En una actividad se manifestó la situación de David, quien fue elegido para representar un grupo. Sin embargo, lo que se tuvo en cuenta para esta elección fue su edad, pues es el niño más grande. Este es un ejemplo de la falta de liderazgo que existe en el aula y de la manera en la que muchas veces participan, pues toman diferentes excusas que usan como justificación para desligarse de una responsabilidad.

\section{Dificultades en la participación}

La concepción que se tiene de participación en el contexto ha generado que sea de manera momentánea. Es decir, su voz se escucha solo en momentos de opinión que no trascienden o se limitan a la repetición de lo que el adulto ha dicho. Una segunda dificultad se relaciona con las consecuencias que tiene la falta de diálogo entre los estudiantes. Las intervenciones se vuelven aportes individuales cuyo objetivo es ser escuchado, pero no escuchar a los demás. Además, al exponer se enfocan únicamente en el maestro, lo cual ha producido que al dirigirse a un grupo más amplío tengan desconfianza y temor. Por último, se evidencia que algunos acudientes sobreponen sus ideas a las de los niños y las niñas, haciéndolos sentir inferiores, inseguros e incapaces. En consecuencia, los estudiantes ven la necesidad de tener aprobación y acompañamiento constante de una persona mayor para las decisiones que deben tomar.

\section{La ciudadanía de los niños y niñas de la IED Marruecos y Molinos}

Se tuvo en cuenta la subjetividad entendida como la percepción, la estética desde las experiencias que generen un sentir y la relación con los otros y lo otro, para evidenciar la ciudadanía de los estudiantes. Para ello, se establecieron varios rasgos que constituyen su ciudadanía: individualidad, competencia, dependencia y fragmentación del sujeto. Estas actitudes ciudadanas se manifiestan, además, en diferentes estereotipos que los niños y niñas tienen del mundo y de las personas. Se encuentra que incluso cuando el adulto es la base en esta construcción subjetiva, en muchos casos la influencia del par transforma los procesos de construcción de ciudadanía.

\section{El ciudadano como un sujeto individualista}

En nuestros contextos persiste la noción de que el ser humano posee al nacer toda una serie de facultades que la educación desarrolla y potencializa a través del papel de las instituciones, tanto de la escuela como el de la familia (cuyas funciones son fortalecer y desarrollar dichas capacidades para formar sujetos productivos para la sociedad, ello desde una perspectiva crítica). Pero, en términos de Villarroel y Sánchez (2002), lo que los niños y niñas aprenden de sus padres no es simplemente el resultado de lo que ellos les han enseñado, sino que reciben también influencias de otros miembros de otros grupos sociales vinculados a la familia. De allí que la personalidad desarrollada de manera posterior dependa de las influencias de los distintos ambientes y sus creencias.

En el colegio donde se realizó la investigación se evidenciaron tres consecuencias de este tipo de formación (la cual se enfoca en una ciudadanía individualista y un sujeto egoísta de lo que piensa y necesita el otro). La primera se manifiesta cuando los estudiantes justifican que si se da la oportunidad de librarse de una sanción es una acción que se debe realizar. Por otro lado, los que no piensan de esta manera se enfocan en la consecuencia, pero no en el compromiso y la responsabilidad de aceptar el error.

Así mismo, algunos estudiantes actúan aprovechándose de sujetos que valoran como débiles, consiguiendo un bienestar individual sin ninguna preocupación por afectar al otro. Se relaciona con un dicho común: "el vivo vive del bobo"; el cual se justifica con: "¿para qué da papaya?". Estas son expresiones 
recurrentes en el mundo adulto y que el niño y niña adopta, además, con acciones que realiza.

Como segunda consecuencia se encontró que la individualidad no permite que en temas ambientales se piense más allá de lo que se percibe a simple vista. Algunos estudiantes demuestran su indiferencia al realizar actos como el botar basura justificándose en que no produce ningún daño en la salud de una persona.

Una tercera consecuencia es la "necesidad" de culpar a los compañeros. Esta acción se realiza para recibir un reconocimiento o por un bienestar individual, además se produce placer al ver el castigo del otro.

La competencia: una característica de un "ciudadano fuerte" Esta actitud es la más recurrente en el contexto. Ya sea con empujar al otro con tal de ser el primero en la fila, prorrumpir en una conversación para ser los primeros en escuchar o la rivalidad al momento de repartir el refrigerio. A pesar de suceder constantemente, no han encontrado una manera de mediar para evitar peleas, por el contrario, esos comportamientos se han naturalizado.

Para Tonucci (1997) el mayor precursor de estos comportamientos es la escuela, pues se vuelve una institución que promueve la competencia. Allí se establece el trabajo individual y desinteresado por lo que realizan los demás. Así mismo, la disposición de educar sujetos individualistas se fortalece con prácticas de crianza enfocadas en el egoísmo y en demostrar que se puede ser mejor que el otro. "Desde la última década hay un énfasis para que los niños desarrollen determinadas competencias como individuos competitivos en una sociedad global" (Hart, 2005, p. 36). El no encajar en este tipo de sociedad puede generar angustia en las instituciones encargadas de la socialización de la infancia. Igualmente, los niños y niñas en cumplimiento de las exigencias de la familia y la escuela crecen buscando su bienestar individual sin importar el daño que le pueda producir al otro.

Cuando el acompañamiento se vuelve dependencia

Para la formación de la ciudadanía es necesario que el niño y la niña vivan sus propias experiencias. Para ello, el adulto debe permitir que tome sus propias decisiones; de esta manera, promoverá una mayor conciencia frente a las mismas. Sin embargo, Miller (1985) destaca que en la pedagogía negra ${ }^{2}$ existen tendencias que el adulto utiliza para que el niño y la niña se sientan inseguros y dependientes a ellos pues lo creen necesarios para su bienestar. Una tendencia en la que prima la necesidad de erradicar la curiosidad y la testarudez de la infancia por seguir sus propias convicciones. En la realidad del contexto escolar encontramos que el educador se dedica a que los niños y niñas aprendan a ser estrictamente obedientes. Esto explica que los estudiantes asistan al maestro frecuentemente para que les diga cómo hacer las cosas, qué se debe decir y cómo se debe actuar; y, de igual modo, quieren tener el consentimiento y buscan ser reconocidos para sentirse satisfechos por lo que han realizado.

Esta característica no solo limita la formación de un pensamiento propio, sino que además hace que pierdan autonomía. Esto puede producir resignación, descontento y malestar (Tonucci, 1997, p. 74), pues muchas veces a pesar de estar en contra de lo que dice el adulto, el niño y la niña realizan exactamente lo que le han pedido.

La mirada que tiene el adulto de la infancia como carente e incapaz, la cual debe ser corregida y protegida (Shier, 2010), limita e imposibilita su accionar en diferentes espacios. De acuerdo con Tonucci (2002), el niño no tiene valor por lo que es hoy, sino que lo gana en cuanto adquiere y aprende ciertos conocimientos y capacidades. Esto provoca que el adulto sea quien asume la responsabilidad y que ellos se desliguen de la situación y no desarrollen estas capacidades. Con dichas situaciones no se promueve su autonomía, ni se posibilita su crecimiento frente a diferentes conocimientos y se limita su formación como ciudadano desde el presente. Se forma desde un sentido de irresponsabilidad, pues encuentra en el adulto a la persona que soluciona sus errores o conflictos y al ser un "menor" puede desentenderse de ello.

No obstante, el mismo autor resalta que se reconoce que los niños dependen fuertemente y por

2 Pedagogía negra es un término acuñado por la psicóloga Alice Miller en la década de 1980 con el que intentaba definir el estilo de educación autoritario que busca doblegar al infante y someterlo a la voluntad de los adultos. 
lo cual es importante contar con buenos adultos, pues es condición indispensable para asegurar una aceptable calidad de vida infantil. A pesar de que esta dependencia no puede dejar de existir, pues es necesaria, debe reconocerse el lugar en el que se debe ubicar el adulto para realizar este acompañamiento.

\section{Padres y docentes en la formación}

\section{de ciudadanos}

La formación de los niños y las niñas ha de ser un proceso conjunto entre el docente y sus familiares. Los profesores, como personas capaces de reflexionar su práctica, deben dar a conocer su saber pedagógico3 con las familias para que la formación de los estudiantes sea conjunta. Así mismo, en las dinámicas escolares se debería procurar realizar ejercicios en los que se unifique el conocimiento de los padres y el proceso de enseñanza de los estudiantes. Así, no solo los vínculos con la familia se fortalecen, sino que permiten una mejor comprensión sobre las formas de enseñanza que llevan sus hijos en el colegio. Sin embargo, son intenciones que muchas veces se quedan en propuestas.

En el proyecto pedagógico se intentó trabajar con los adultos que acompañan a los niños y niñas en sus hogares. Se tuvo como propósito tener coherencia entre lo que se veía en la escuela con lo que hacían en sus casas. En un inicio las familias demostraron interés por las actividades realizadas, pero al final se desligaron del proceso. Un ejemplo de ello sucedió con la puesta en escena de una obra de teatro en la cual se les pidió a los familiares apoyo usando materiales reciclables para la construcción de los atuendos que usarían los actores; pero, para el día de la obra, la mayoría de los niños y niñas usaron vestidos ya hechos, construidos con materiales nuevos o simplemente no llevaron.

Los intereses y disposiciones de los familiares a involucrarse en el aprendizaje de sus hijos, así como la dificultad que existe en cambiar los

3 Se refiere a la reflexión y construcción de un conocimiento propio a partir del trabajo investigativo con los niños y las niñas acerca de su participación y ciudadanía. hábitos, fue un obstáculo para lograr el objetivo. No obstante, se resalta que el conocimiento que los padres dan a los niños y niñas son fundamentales en la apropiación del espacio, así como también en otros procesos de aprendizaje. En esta medida, el acompañamiento que hicieron algunos padres en distintos ejercicios resultó en dinámicas enriquecedoras, no solo para los estudiantes, sino también para las docentes. Por ejemplo:

Una mamá en una actividad hablaba sobre las clases de árboles que podían encontrarse. Se llegó a un árbol, en el que ella se detuvo para contar que cuando vivió en el campo estos frutos eran utilizados como purgantes.

Como ya se ha mencionado, el adulto forma parte importante de la construcción subjetiva de los niños y niñas, los cuales repiten y se comportan según estos "modelos". Por esta razón, para que se promueva un aprendizaje y un cambio frente a su ciudadanía es necesario un trabajo con los adultos que concurren su cotidianidad. Las dificultades del tiempo, acompañamiento y disponibilidad de la familia deben superarse para que la enseñanza en la escuela no sea contraria a lo que realiza en el hogar.

\section{Fragmentación del sujeto: una consecuencia de la estructura social}

A partir de la propuesta pedagógica se manifestó un fenómeno en los estudiantes, la cual se caracteriza por la falta de coherencia entre lo que se dice (discurso) y lo que se hace (acción). A este fenómeno se le ha denominado fragmentación del sujeto. Es recurrente que los niños y niñas repitan un discurso, pero al momento de poner en acción lo dicho son totalmente incongruentes; caso contrario de los que no expresan verbalmente lo trabajado, pero en su accionar son bastante activos. Aunque la mayoría de los estudiantes reflexionaron y adoptaron discursos que les permitió ir más allá de una simple repetición, cuando tienen que ponerlos en práctica vuelven a los comportamientos acostumbrados.

Desde Bourdieu y Passeron (2009) este fenómeno sucede porque las condiciones sociales, 
los recursos económicos y culturales de los que disponen los niños y las niñas les proporcionan experiencias vitales, Ilevándolos a patrones de comportamiento específicos, los cuales entran a ser fragmentados en los dos niveles de socialización. El primero inicia en el contexto familiar, cuyos aprendizajes se enmarcan en la construcción de lo moral, repitiendo las conductas del adulto como una acción válida; y el segundo en un contexto escolar, el cual le brinda un aprendizaje desde un conocimiento científico. La repetición de discursos se vuelve rutinario. De esta manera, el habitus es el conjunto de disposiciones por las cuales los individuos producen y reproducen esa estructura social. En este caso los estudiantes reproducen un discurso que la escuela le brinda aun cuando sea alejado de sus prácticas diarias.

Como lo cita Santos (2006) gran parte de lo que se aprende en la escuela no se siente como algo propio, así el conocimiento escolar puede resultar ajeno e inútil. Por esta razón los niños y las niñas sufren una fragmentación, ya sea en términos de un discurso y su acción o de las maneras en cómo se relaciona en la escuela y en su contexto. Como modo de solución a dicha situación Usagui (2005) cita a Durkeim y Freire mencionando la importancia de establecer la socialización diferencial entre la escuela y la estructura social. De esta manera, el estudiante va descubriendo la relación dinámica, fuerte y viva entre palabra y acción, entre palabra-acción-reflexión, entre lo aprendido en la escuela y fuera de ella. En el trabajo investigativo lo anterior se vio reflejado cuando los niños y niñas relacionaban las situaciones vividas con las temáticas trabajadas en el aula. En esta medida se evidencia cómo el aprendizaje logró ser significativo para los estudiantes.

\section{Construcción del pensamiento a partir}

de la influencia del otro

Se defiende la idea de que las actitudes construidas por los sujetos son influenciadas por sus experiencias y personas cercanas. Se señala la primera influencia: el contexto familiar, esta es la base en la cual aprende y toma de modelo. Por ello, fue importante cuestionar y comprender los modos como la familia permite que ellos participen y se formen como ciudadanos dentro del hogar. A la pregunta por estos modos, la mayoría de las respuestas corresponden a un tipo de participación en la que se le incluyen hasta cierto punto en las actividades y se les otorga una responsabilidad que comparten con los demás miembros de la familia; como, por ejemplo, barrer, trapear, etc. Se encuentra también la desconfianza en las capacidades de los niños para apoyar en las dinámicas familiares.

Directamente en el contexto escolar, las experiencias pedagógicas permitieron comprender la representación del mundo que los estudiantes tienen en la que categorizan a los demás de acuerdo con los modos de vestir, sus profesiones o incluso un rango de edad. Estos estereotipos definen a las personas dentro de la sociedad como buenas o malas. En términos de representaciones los niños y niñas tienen diferentes ideas respecto a las profesiones y ocupaciones de las personas, enmarcando a unas como superiores a las otras; un ejemplo es el deporte profesional, el cual es visto como bueno porque provee de popularidad y dinero.

Las representaciones de la sociedad hacen que en su construcción subjetiva se incorpore la idea de que sea válido actuar con violencia en situaciones conflictivas. En una actividad un estudiante justifica el golpear o matar a una persona por una acción negativa que ha realizado, como, por ejemplo, robar. De esta manera, se manifiesta una actitud en la que define a un buen ciudadano como aquel que ayuda al otro sin importar el acto violento. Como consecuencia en el proceso de formación ciudadana los estudiantes crecen con la noción de que se debe ser alguien capaz de defenderse y defender a los demás, aunque esto implique afectar a otra persona.

A pesar de que la mayor influencia en la construcción subjetiva de los niños y las niñas se da por parte del adulto, por medio de la intermediación que realizan con sus pares en el día a día en la escuela logran configurar las construcciones de sus compañeros. Así, se vuelven grandes influyentes en la constitución del sujeto y resultan ser un factor importante en sus decisiones.

Por otro lado, los niños y las niñas son sujetos capaces de influenciar en el pensamiento del adulto. Durante el desarrollo del proyecto pedagógico 
se evidencia un proceso de enseñanza entre estudiantes y docente. Se destacan dos ejemplos claves. En el primero, los estudiantes argumentan ante la negación de la docente para realizar la interpretación de Maléfica, pues:

[...] en la obra también se puede desperdiciar el agua y botar basura. No todo puede ser obras de naturaleza.

Esta experiencia permitió pensar que el aprendizaje es también la complejización de un conocimiento cotidiano a un saber científico, en el que el niño y la niña puedan transformarlo para que sea significativo.

El segundo ejemplo se presenta en una actividad de creación. El estudiante pasó al frente e interpretó una canción de reggaetón. Las docentes en formación cuestionan la importancia de esto sobre el tema del proyecto. La posición del niño es firme y justifica que escribiendo canciones también se aprende. La respuesta del estudiante logró poner en reflexión cómo las canciones pueden incluirse dentro de las estrategias metodológicas.

Como bien dice Hoyuelos (2006), la dimensión estética es parte fundamental de la construcción de las estructuras del pensamiento, pues en ella se configura la mirada que se tiene frente al mundo, con los otros y de sí mismos. De acuerdo con esto, los niños y niñas tienen una percepción de sí a partir de estas construcciones, los cuales configuran una manera de estar y actuar. Según el discurso del adulto se encuentra que los estudiantes pueden llegar a sentirse en un nivel inferior, así como en un nivel más alto a comparación de compañeros de menor edad. Esto ha generado unas relaciones de poder que configuran las interacciones que se dan con el otro.

\section{Relaciones de poder}

La primera es entre ellos mismos, probablemente porque ven debilidad en el otro, construyendo así unas maneras de ser en la escuela que les permite ejercer cierta autoridad o ser subordinados. La edad resulta ser un factor importante en esta relación. Para Gaitán (1998, citado en Martínez, 2003) los papeles en el interior de la sociedad definen unas relaciones de poder producidas por la discriminación basada en criterios de edad. Significa que las relaciones asimétricas que se establecen al interior de una comunidad no deben ser comprendidas como "naturales" y por tanto inmodificables, pues son construidas culturalmente (p. 49). En este sentido, los niños y niñas se perciben con mayores conocimientos, capacidades y hasta inteligencia respecto a compañeros más pequeños. En cuanto a la relación con los adultos, ellos se asumen como inferiores, viéndolos como una persona con mayor poder.

También se explica con Tonucci (2002) cuando expresa que los adultos que acompañan el desarrollo de los niños y las niñas los consideran como sujetos que tienen un valor por lo que serán y no realmente por lo que son en el presente. Esta mirada del adulto hacia el niño en el contexto de la investigación produce en ellos no solo que se perciban de esta manera, sino que ejerzan estas mismas actitudes con sus compañeros de edades menores.

Las estructuras de jerarquía se dan también con otros comportamientos o actitudes. La frase "llegó la profe" hace que todos vuelvan a sus puestos y se muestren organizados. Contrario a lo que es con las docentes en formación que se muestran indiferentes con su disposición para las actividades.

Contrario a lo que es con las docentes en formación, pues los estudiantes en algunos casos son indiferentes y no muestran mayor relevancia si se acerca alguna de ellas, continuando con la misma actitud de juego y desorden en el salón.

Los cambios en las dinámicas del aula hacían creer a los estudiantes "que podían hacer lo que quisieran". Frente a ello se cuestiona lo que es ser un buen docente, pues uno de los propósitos del proyecto era mantener un trato respetuoso con los estudiantes sin la necesidad de acudir a mecanismos de control. Sin embargo, en las intervenciones fue necesario retomarlas como una medida que ayudó a mejorar las actividades. Estas situaciones muestran algunas contradicciones que se presentaron pues, aunque se tenía una intención, en el trabajo pedagógico se dificulta dejar atrás aquellas estrategias tradicionales. 
Transformaciones durante el trabajo pedagógico En el proyecto pedagógico se propusieron ejercicios con los que se promovió transformaciones en los estudiantes frente a sus maneras de participar y su ciudadanía. Exponer un tema de interés en cada clase evidenció que los conocimientos previos de los estudiantes son la mayor fuente de interés al momento de participar, ya que propicia la capacidad de escucha (lo cual también incita a la reflexión y conlleva a cambios al momento de respetar la palabra del otro en la interacción en el aula). Así, no solamente se genera respeto entre ellos, sino que se fortalecen aquellos conocimientos que cada uno tiene.

De igual manera estos ejercicios permitieron otro tipo de acercamiento entre el docente y el estudiante. Se pone como ejemplo una pregunta realizada: ¿los niños también pueden enseñar a las profesoras? Primero, los estudiantes dijeron que no, pero al recordar el trabajo en las sesiones comentaron: "los niños pueden saber una cosa que la profesora no sabe", "un profesor se puede equivocar y un niño le puede ayudar", "los profesores saben más que los niños, pero a veces se equivocan". De esta manera, cuando se posibilita un espacio para decir lo que piensan ellos, encuentran puntos importantes en la que su voz es fundamental para el aprendizaje.

Las estrategias metodológicas también enriquecieron los procesos de enseñanza o de organización en el aula. El manejo de voz como forma de llamar la atención del estudiante propició la capacidad de escucha. La integración de estudiantes al proyecto pedagógico fortaleció su participación, así como su capacidad de relacionarse con el otro y la seguridad en sí mismo al presentar sus propuestas.

Los cambios más evidentes al final del proyecto pedagógico se dieron en la noción de participación. Algunos estudiantes comprendieron la acción de participar ya no solo dentro de las dinámicas académicas, las cuales consisten en opinar, alzar la mano y contestar las preguntas, sino también en la participación en actividades complementarias y espacios fuera del contexto escolar. Un ejemplo de ello se dio cuando una estudiante en una entrevista comentó que ella ha participado por medio del dibujo y las obras de teatro en actividades en las cuales los niños podían decidir de qué manera participar.

Se fortalecieron procesos de autonomía, responsabilidad y trabajo colaborativo. Los niños logran acordar con sus compañeros un ejercicio conjunto trabajado en un mismo espacio como es el papel. Tuvieron iniciativa para proponer lo que querían expresar sin esperar a que el adulto le indicase qué hacer. Así, pues, se evidencia que progresivamente fueron adoptando aptitudes que les permitieron proponer desde sus mismos intereses y conocimientos. Aunque algunas veces seguían dependiendo de la opinión del docente, esto ocurrió en menor medida. Ya no esperan que se les diga qué hacer, sino que al preguntar lo hacen con una propuesta.

A partir de los diferentes ejercicios de sensibilización, algunas nociones de los estudiantes se transformaron a pequeños acercamientos de lo que sería una ciudadanía planetaria. Algunos comentarios de los estudiantes frente a cuestionamientos sobre el uso de la basura demostraron que no solo piensan a partir de lo que los afectaba directamente, sino que relacionan las acciones que se realizan en el contexto local con las consecuencias que se dan en el contexto global. En las entrevistas, al cuestionarlos acerca de botar basura en el colegio o en la quebrada, resaltaron las consecuencias que tienen en los animales $u$ otros lugares lejanos a su contexto. En este sentido, también se logró establecer un cambio frente a la relación con lo otro. En sus respuestas, al preguntar acerca de lo que hace ser un buen ciudadano los niños resaltaron el buen trato; por ejemplo, un niño a la pregunta formulada respondió "no decirle groserías con los que se pelea".

Aun cuando las niñas y los niños actúan y toman una posición frente a diferentes espacios, existe dificultad al expresar lo que es para ellos participación y ciudadanía. La noción de ciudadanía lo asocian con el proyecto desarrollado y cuando se les preguntaba qué era ser un buen ciudadano se obtenían respuestas como "es el que cuida el planeta y el que no gasta el agua". Aunque no lograron establecer una diferencia clara entre ciudadanía planetaria y otros tipos de ciudadanía, ellos comentan que en la primera "se tiene que hacer un poquito más de trabajo". 


\section{Conclusiones}

En la actualidad hace falta consolidar la reflexión sobre qué tipo de ciudadanos estamos formando. Algunos niños y niñas crecen bajo dinámicas de dominación, represión y competencia, pues no se ha comprendido el valor que tiene la participación infantil. De allí la consecuencia de no poder cambiar los tipos de relación que se tiene con el otro y lo otro. Por esta razón, el proyecto de investigación trabajó la ciudadanía planetaria como un nuevo paradigma que da soluciones a dichas problemáticas. Sin embargo, en el contexto se manifestaron dos grandes dificultades: la participación de la infancia es poca, por no decir que nula; y el concepto de ciudadanía planetaria es apenas conocido. En consecuencia, se encuentra una ciudadanía irresponsable con el ambiente e insensible con el otro. Aun así, el proceso pedagógico permitió que gradualmente los estudiantes al momento de participar fueran capaces de proponer y transformar su accionar en un contexto inmediato. A pesar de no tener una comprensión clara sobre la importancia del por qué y para qué participan, los ejercicios promovieron una reflexión sobre la participación de los demás compañeros.

Es necesario un acompañamiento por parte del docente o adulto que fortalezca sus ideas y los ayude a empoderarlas. En esta medida, se resalta la participación de la familia en los procesos de aprendizaje de sus hijos. No solo porque permite un acercamiento de las dinámicas educativas y permite un mayor conocimiento de la enseñanza, sino porque se establece una relación en la que se puede trabajar juntos, padres y docentes, para el bien común de los niños y las niñas.

La experiencia pedagógica permitió comprender la relevancia y pertinencia que tiene promover la participación en la formación de la ciudadanía. La pedagogía de la pregunta es un medio que permite incentivar a los niños y niñas a que se cuestionen, propongan y argumenten. En este sentido, al evidenciar el impacto que tuvo el proyecto pedagógico y las diferentes estrategias utilizadas en él, es oportuno que se mantenga un proceso con los niños y niñas en el que se promuevan otros tipos de participación y se incentive para que cada estudiante logre encontrar la manera en la que se siente mejor para hacerlo. Como bien se ha visto, la idea de participación en el levantar la mano y responder debe expandirse en el compartir con otros estudiantes, en expresarse por medio de experiencias estéticas y en realizar otro tipo de actividades fuera del aula; lo que permite que relacionaran las situaciones vividas con las temáticas trabajadas en el proyecto de aula.

Ser docentes es ser sujetos de transformación, comenzando por sí mismo, para luego formar a nuestros estudiantes. Esta experiencia no solo permite ganar un mayor conocimiento frente a nuestro papel en el aula y de la misma enseñanza, sino a comprendernos mejor como maestros, como seres en continua construcción y transformación. Porque cada experiencia, cada momento y palabra logra configurarnos como sujetos que actuamos con otros.

En este caso, comprender que ser ciudadano planetario no es algo que se pueda imponer, sino que se debe enseñar y que para ello es necesario reconocer al otro como un sujeto igual. Por lo cual, esta formación implica no solo pretender que los niños y niñas lleguen a una ciudadanía planetaria, sino que como docentes debemos vivirla primero.

\section{Referencias}

Boff, L. (1996). Ecología: grito de la Tierra, grito de los pobres. Trotta.

Bourdieu, P. y Passeron, J. (2009). Los herederos, Los estudiantes y la cultura. https://proletarios.org/books/Bourdieu-Los_herederos_los_Estudiantes_y_la_Cultura.pdf

Elliot, J. (2000). La investigación-acción en educación. Morata. http://www.terras.edu.ar/biblioteca/37/37ELLIOT-Jhon-Cap-1-y-5.pdf

Freire, P. (1986). Hacia una pedagogía de la pregunta. Conversaciones con Antonio Faundez. Ediciones La Aurora.

Gadotty, M (2000). Pedagogía de la Tierra. Siglo $\mathrm{XXI}$.

Gadotty, M. (2000). Pedagogía de la Tierra y cultura de la sustentabilidad [conferencia]. En Comisión Costa Rica 2000 (org.), Foro sobre nuestros retos globales: un nuevo milenio de paz "Si vis pacem, para pacem". Universidad de la Paz, San José de Costa Rica. 
Gallego-Henao, A. M. (2015). Participación infantil... Historia de una relación de invisibilidad. Revista Latinoamericana de Ciencias Sociales, Niñez y Juventud, 13(1), 151-165. https://doi. org/10.11600/1692715x.1318060514

Hart, R. (1992). La escalera de la participación infantil. PAU Education. http://www.formacionsve.es/salida/documentos/17.pdf

Hart, R. (1993). La participación de los niños: de la participación simbólica a la participación auténtica. Ensayos Innocenti, 4. Fondo de las Naciones Unidas para la Infancia (Unicef), Oficina Regional para América Latina y el Caribe.

Hart, R. (2001). La participación de los niños en el desarrollo sostenible. Unicef, PAU Education.

Hoyuelos, A. (2006). La estética en el pensamiento de Loris Malaguzzi. Ediciones Octaedro, S. L.

Jaramillo, S. y Mejía, M. (2019). La participación de los niños y las niñas para la construcción de ciudadanos planetarios (tesis de pregrado). Universidad Distrital Francisco José de Caldas. Repositorio Institucional UD. http://hdl.handle.net/11349/22087

Leff, E. (2000). La complejidad ambiental. Siglo XXI.

Leff, E. (2001). Espacio, lugar y tiempo. La reapropiación social de la naturaleza y la construcción local de la racionalidad ambiental. https://doi.org/10.5380/dma.v1i0.3057

Martínez, M. (2003). Capítulo 4: Protagonismo infantil. De la participación al protagonismo infantil. Propuestas para la acción (pp. 47-53). Plataforma de Organizaciones de Infancia.

Miller, A. (1985). Por tu propio bien. Raíces de la violencia del niño. Tusquest.
Morin, E. (1999). Los siete saberes necesarios a la educación del futuro. Paidós Ibérica, Unesco.

Parra, C. (2002). Investigación-acción y desarroIlo profesional. Educación y Educadores, 5, 113-125.

Restrepo, B. (2004). La investigación-acción educativa y la construcción de saber pedagógico. Educación y Educadores, 7, 45-55. http://www.redalyc.org/pdf/834/83400706.pdf

Saturnino, S. (2017). El hábitus una revisión analítica. Revista Internacional de Sociología, 75(3). https://doi.org/10.3989/ris.2017.75.3.15.115

Shier, H. (2010). Teoría de la participación infantil y su relevancia en la práctica cotidiana. En Incidencia de niños niñas y adolescentes como ciudadanos/as activos/as en Nicaragua (pp. 1-10). Cesesma, Universidad del Norte de Nicaragua.

Tonucci, F. (1997). La ciudad de los niños. Un modo nuevo de pensar la ciudad. Fundación Germán Sánchez Ruipérez.

Tonucci, F. (2002). Cuando los niños dicen ¡basta! Fundación German Sánchez Ruipérez.

Usagui, E. (2005). Durkheim: conflicto y educación. Universidad del País Vasco. http://institucional.us.es/revistas/cuestiones/17/ art_17.pdf

Villarroel-Sánchez, R. X. (2002). Relación familia y escuela: un estudio comparativo en la ruralidad. Universidad de Playa Ancha de Ciencias de la Educación. https://doi.org/10.4067/ S0718-07052002000100007

Zabalza, M. (1998). El practicum en la formación de maestros. En La formación de maestros en los países de la Unión Europea.

Zuleta, O. (2005). La pedagogía de la pregunta. Una contribución para el aprendizaje. Educere, 9(28), 115-119.

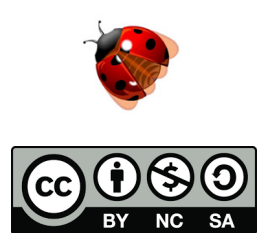

Esta obra está bajo licencia Creative Commons Atribución-NoComercial-Compartirlgual 4.0 Internacional 